\title{
Kinetics of Internal Methane Steam Reforming in Solid Oxide Fuel Cells and Its Influence on Cell Performance- Coupling Experiments and Modeling
}

\author{
L. Fan, M Pourquie, A.T. Thattai, A.H.M. Verkooijen and P.V. Aravind \\ Department of Process \& Energy, Delft University of Technology, Delft 2628 CA, the \\ Netherlands
}

\begin{abstract}
Mathematical modeling tools are useful for predicting the safe operation limits and efficiencies of SOFCs. For a particular SOFC design, variations in internal methane reforming kinetic parameters is expected to affect local gas compositions, local Nernst voltages, current densities and temperature profiles and in turn the safe operation limits and efficiency. However, it is observed that methane reforming kinetic data widely used in SOFC CFD models are often determined from measurements on nickel catalysts taken under experimental conditions not close enough to SOFC operation conditions causing significant inaccuracies in model calculation results. For this reason, kinetic properties of the methane steam reforming reaction in complete fuel cells with $\mathrm{Ni}-\mathrm{GDC} \quad\left(\mathrm{Gd}_{0.1} \mathrm{Ce}_{0.9} \mathrm{O}_{2}\right)$ anodes were experimentally evaluated. SOFCs with different anodes made of different materials may perform differently due to the different reforming kinetics and the different thermal properties.
\end{abstract}

\section{Introduction}

Fuel cell technology appears to be a promising generation of novel power sources. One of the essential advantages for the efficient operation of solid oxide fuel cells (SOFCs) is the flexible choice of fuel. Under certain conditions, natural gas or biosyngas (including $\mathrm{CH}_{4}$ ) can be introduced into SOFCs directly as fuel gases without any external reformers (1). This is because the SOFC anodes can catalyze the steam reforming of $\mathrm{CH}_{4}(2-5)$. With internal steam reforming, solid oxide fuel cell (SOFC) systems have the potential to become a promising technology $(6,7)$. A large variation of steam reforming kinetics is provided in literature, and the experimental data are obtained under different conditions $(3-5,8,9)$. Influence of different reforming kinetics combined with different thermal properties on the cell performances is still unknown.

Mathematical modeling is an effective tool to facilitate predicting appropriate design of fuel cell systems. A CFD model of a biogas (obtained from biomethanation) fueled SOFC is studied by G. E. Marnellos et al (10), and an improved understanding of the involved physical, electrical, and chemical processes was given. P. Aguiar et al (11) have simulated the steady-state performance of anode-supported intermediate temperature SOFCs. Q. Cai et al (12) have modeled the 3D microstructure and performance of SOFCs. The study of different kinetic for internal reforming reactions by CFD in anode-supported SOFCs by Hedvig Paradis et al (13) enhanced the understanding of the internal reforming reactions and their effects on the transport processes. However, to better understand the relationship between reforming kinetics and the cell performance, a more detailed 
modeling is helpful (13-17). The model used in this study was first built by Qu et al (17, 18) by adopting a three-dimensional modeling approach in which heat sources are derived from the methane steam reforming reaction and the water-gas shift reaction (1417).

Relatively few studies on the internal reforming reaction in SOFCs with $\mathrm{Ni}-\mathrm{GDC}$ anodes have been published $(1,9,19)$. The internal reforming of methane on Ni/CGO and $\mathrm{Ni} / \mathrm{YSZ}$ anodes was investigated by $\mathrm{H}$. Timmermann et al (9) with single cells operated at steam to carbon ratios from 0 to $3\left(800{ }^{\circ} \mathrm{C}\right.$ to $\left.950{ }^{\circ} \mathrm{C}\right)$. With the Ni-CGO anode, the reaction order for methane was 1.19 under this operation regime, and the apparent activation energy was observed to be $26.3 \mathrm{~kJ} / \mathrm{mol}$. A one-dimensional model was used to describe the gas composition along the gas channel of the Ni-CGO anode. However, most of the reported kinetic studies were performed either on just the electrode materials or on the electrode instead of a full fuel cell, which cannot precisely simulate fuel cell conditions $(3-5,8,9,19)$. The kinetics of the internal methane steam reforming in SOFCs are seldom studied, especially under working conditions. In this paper, the simulation results observed on different anode materials under open-circuit working condition from both literature and our experiments are discussed in detail.

\section{Background}

The development of SOFCs is still facing a lot of challenges in fuel flexible operation and a better understanding of the internal steam reforming reaction (1) is useful. When feeding the SOFCs with carbon fuels such as methane, the influence of the kinetics of the steam reforming reaction is drawing more and more attention. Carefully controlling the steam reforming rate can draw better performance of the SOFCs, such as more even temperature gradient, higher efficiency $(16,17)$. Modeling work can give an overall preview of the performance, and thus give suggestions to the cell design and can be also a guide for the operating condition selection. Experimental validation is necessary and very important to the development of the SOFCs $(9,19)$. Detailed experiments for the kinetic parameter measurements for steam reforming reaction should be carefully designed and conducted. To date, good combinations of model and experimental data are rarely reported $(3,4,9,19,20)$. Therefore, the objective of this study is to adopt reliable experimental data into our model (14-17), and thus to get a better predicted performance of SOFCs.

The fuel flexibility of SOFCs described in the model has been studied by investigating a case of biosyngas (15). Theoretical prediction of the nickel oxidation and the carbon deposition are also employed to give a calculated possibility of the unsafe SOFC operation regarding carbon deposition and nickel oxidation. The biosyngas fueled cell shows a reasonable performance compared with the hydrogen-fueled cells. It also shows that the methane steam reforming kinetics has a significant influence on the performance even with a small amount of methane in the biosyngas. Therefore, the activation energy for the internal steam reforming reactions of methane on the cell performance has been investigated in detail (14) by carefully studying literature on the steam reforming reaction kinetics from experimental investigations and by selectively applying the findings into this model. All the simulated results are meaningful for the conducting useful SOFC experiments. 
Detailed experimental study of the steam reforming kinetics with a relatively close set-up description can give a better view of the relationship between the reforming kinetics and the performances. However, systematic experimental data for the steam reforming reaction are scarce (9). With varied inlet gas compositions, a complete planar SOFC with a Ni-GDC anode that is close to our model has been used to study the kinetic parameters under open-circuit working condition. The activation energy and the preexponential factor for the methane steam reforming reaction on the Ni-GDC anode have been obtained. The experimentally obtained data together with the experimental data in literature for different anode materials are then adopted into the model in this study, and the simulation results are discussed in detail. Further experiments are now still undergoing (see more details in the submitted paper: Kinetic study of the methane steam reforming in an open-circuit solid oxide fuel cell, International Journal of Hydrogen Energy, under review).

\section{Model and Experiments Descriptions}

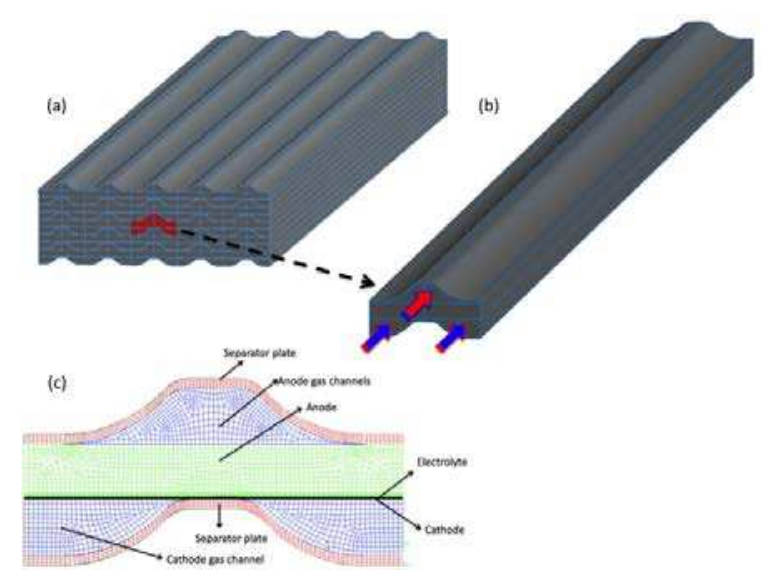

Figure1. Corrugated single channel model: (a) Fuel cell stack schematic diagram; (b) single channel schematic diagram; (c) cross-section with CFD grids for the single channel.

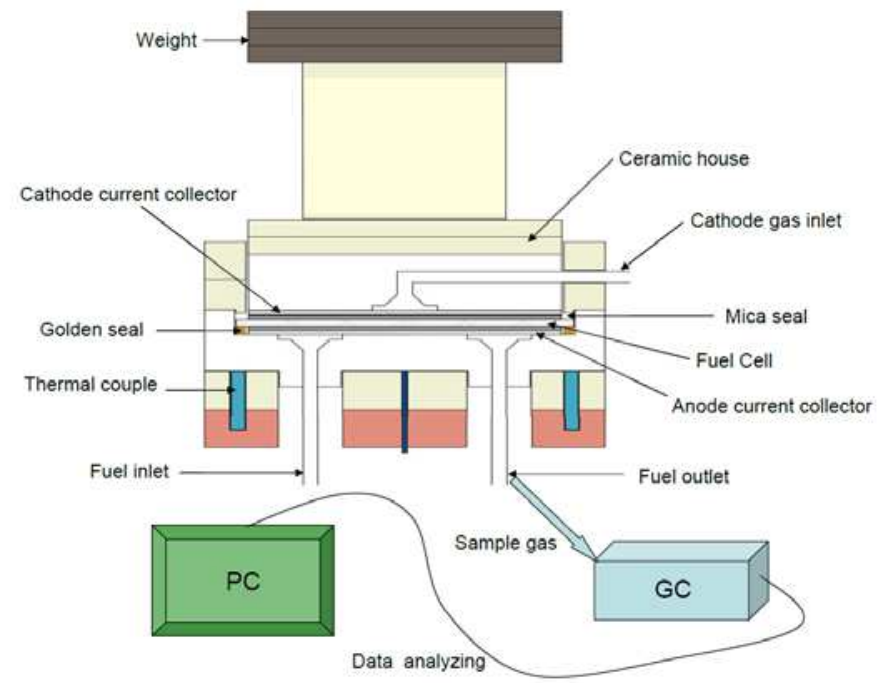

Figure 2. Experiment scheme. 
The geometry of the model represented in this work is shown in Fig. 1. The model developed in this work considers a representative single channel unit in the stack is assumed to be in the centre of a large stack, so that no end effects from the sidewalls are present. The simulation of the single channel is supposed to be representative of the behavior of the whole stack, except for the channels at the edges of the stack where boundary conditions and the active cell area are different, as shown in Fig. 1(a). The present model is based on the co-flow design, in which anode gas and cathode gas flow are in the same direction on both sides of the cell, as shown in Fig. 1(b). Fig. 1 (c) shows the cross section of the single cell unit and the grids for the model calculation. The model input data and the operating parameters of the presented model can be found from our previous work $(14,15)$.

For the experiments, complete fuel cells with a single Ni-GDC anode are used. The planar fuel cell is $9 \times 9 \mathrm{~cm} 2$, electrolyte-supported; the thickness of the anode is $35 \mu \mathrm{m}$. The anode material used in this study was Ni-GDC with a functional layer that consisted of nickel and Gd0.1Ce0.9O2 (10GDC). The detailed description for the installation and experimental procedures are reported below, and shown in Fig. 2.

Dry gas flows are controlled with Mass Flow Controllers (MFC) from Bronkhorst. Water vapour is added by controlling the steam flow through a CEM flow controller from Bronkhorst at $75{ }^{\circ} \mathrm{C}$. The cell is heated and reduced by the following procedures: after heating the cell to $800{ }^{\circ} \mathrm{C}$ in nitrogen, a reducing environment is applied to the anode following the duration time and gas composition in TABLE I:

TABLE I. Gas Compositions and Duration Times for the Cell Reducing Procedures.

\begin{tabular}{ccc}
\hline Duration [min] & Nitrogen [mln/min] & Hydrogen [mln/min] \\
\hline 15 & 475 & 25 \\
5 & 450 & 50 \\
5 & 400 & 100 \\
5 & 300 & 200 \\
5 & 200 & 300 \\
5 & 100 & 400 \\
5 & 0 & 500 \\
\hline
\end{tabular}

*The temperature is considered the same throughout the cell.

The off gas passes though a condenser and an absorber to remove all the water. Then a Gas Chromatograph (GC) is used to analyze the off-gas composition. The inlet anode gas compositions can be found in TABLE II, and the cathode gas compositions is simulated air (20\% oxygen and $80 \%$ nitrogen). Methane conversion should not be complete in the system to ensure that the measured reaction rate is the average reforming reaction rate along the cell. To ensure that, methane should be always detected in the offgas by GC. The investigated working condition in this study is under open-circuit.

TABLE II. Overview of the Anode Gas Compositions at Standard Conditions and the Range Each Gas is Varied in.

\begin{tabular}{ccccc}
\hline $\begin{array}{c}\text { Anode gas } \\
\text { composition }\end{array}$ & $\begin{array}{c}\text { Methane } \\
{[\mathbf{m l n} / \mathbf{m i n}]}\end{array}$ & Steam [mln/min] & $\begin{array}{c}\text { Hydrogen } \\
{[\mathbf{m l n} / \mathbf{m i n}]}\end{array}$ & $\begin{array}{c}\text { Nitrogen } \\
{[\mathbf{m l n} / \mathbf{m i n}]}\end{array}$ \\
\hline Flow rate & $220-300$ & 450 & 80 & Balanced * \\
\hline
\end{tabular}

* The total flow rate is $1020 \mathrm{mln} / \mathrm{min}$, balanced by nitrogen which is also a tracing gas for the experiments; temperature ranges from $650{ }^{\circ} \mathrm{C}$ to $750^{\circ} \mathrm{C}$. 


\section{Results and Discussion}

\section{Experimentally Observed Rate Expression}

Notably, the steam reforming reaction rate expression found is only intended as a formula describing of the observed conversions; as such, mass transport limitations and temperature gradients are lumped into the formula. A power-law expression is fit to the measured data using a methane rate order of 0.70 and a steam rate order of 0.42 in Eq. [1] (see more details in the submitted paper: Kinetic study of the methane steam reforming in an open-circuit solid oxide fuel cell, International Journal of Hydrogen Energy, under review):

$$
r=k C_{C_{4}}{ }^{0.70} C_{\text {steam }}{ }^{0.42}
$$

\section{$\underline{\text { Activation Energy }}$}

For further analysis we assumed Arrhenius type of temperature dependence of $\mathrm{k}$. Based on our observations, the activation energy and the pre-exponential factors for methane steam reforming have been determined by data fitting. The activation energy of the steam reforming reaction on the Ni-GDC anode in the fuel cell is found to be 44.42 $\mathrm{kJ} / \mathrm{mol}$, and the pre-exponential factor is $9.20 \times 106 \mathrm{~mole} /(\mathrm{s} \mathrm{m} 2 \mathrm{~Pa} 0.7)$. However, the activation energy obtained in this experiment is higher than the reported value of 26.3 $\mathrm{kJ} / \mathrm{mol}$ tested on a Ni-GDC anode (9). The activation energy measured here is also the apparent activation energy (9). The activation energy was measured in a full fuel cell with a Ni-GDC anode and was significantly less than the previously reported values measured using Ni-YSZ anodes in SOFCs $(4,21,22)$. This discrepancy may be caused by the doped ceria in the anode (23), different morphologies, different particle sizes and different distributions of nickel in the anode than those used in the reactors or in the reaction beds used to study the intrinsic kinetic parameters for the methane steam reforming reaction.

\section{Experimental Data from Literature}

In order to make comparisons on the influence of reforming kinetics on the cell performance, we calculated the performance of the cell with our model using both the experimental data from literature $(3,9)$ and the experimentally observed reforming kinetics from our test-station. The reforming kinetics and the thermal conductivity for different materials are summarized $(24,25)$ in TABLE III:

TABLE III. Experimental Data Used in the Model for Different Anode Materials

\begin{tabular}{lccc}
\hline Anode materials & $\begin{array}{c}\text { Activation } \\
\text { energy } \\
{[\mathbf{k J} / \mathbf{m o l}]}\end{array}$ & $\begin{array}{c}\text { Pre-exponential } \\
\text { factor }\end{array}$ & Thermal conductivity [W/(m K)] \\
\hline (I) Ni-YSZ (3) & 82.00 & $1.07 \times 10^{10}$ & 1.86 \\
(II) Ni-GDC 1 (9) & 26.30 & $6.20 \times 10^{6}$ & 2.19 \\
(III) Ni-GDC2 & 44.42 & $9.20 \times 10^{6}$ & 2.19 \\
\hline
\end{tabular}

* (I) Tested on a Ni-YSZ anode by E. Achenbach at al in 1994.

(II) Tested on a commercial Ni-GDC anode in a complete cell by H. Timmermann et al in 2006.

(III) Tested on a Ni-GDC $\left(\mathrm{Gd}_{0.1} \mathrm{Ce}_{0.9} \mathrm{O}_{2}\right)$ anode in a complete cell in Delft University of Technology. 
Predicted Cell Performance with Different Reforming Kinetics on Different Anode Materials

Gas Compositions along The Channel. Figs. 3-7 show the mole fractions of gas species along the anode gas channel with different anode materials and different activation energies. The gas concentrations are affected by direct methane reforming reaction and the water-gas shift reaction at the anode. Due to the different materials and the different kinetic parameters, the methane steam reforming and the water-gas shift reactions vary a lot. Concentrations of every gas species in anode channel are compared and discussed in detail.

Comparison of methane concentrations for three cases is shown in Fig. 3. Methane concentration decreases rapidly because the reaction can happen much faster when the activation energy is within a certain range (14). As shown in Fig. 3, the main observations among three cases are: (i) the steam reforming reaction rate in case II is faster compared with the other two cases within the first half of the channel; (ii) almost all methane is consumed in the methane steam reforming reaction in three cases at the outlet of the channel; (iii) case I and case III show similar reforming behaviors, though they use different anode materials with different reforming kinetic parameters and different thermal properties. Therefore, the cell performance is influenced by both kinetic parameters, thermal and electrical conductivities.

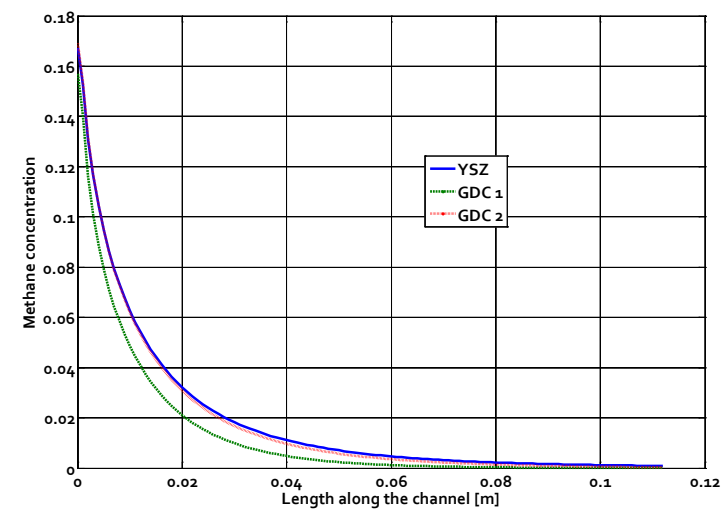

Figure 3. Comparison of methane concentrations along the length of the anode gas channel.

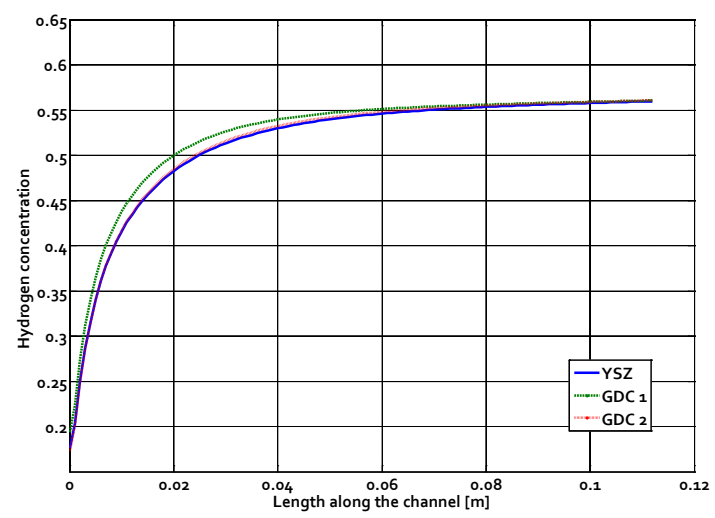

Figure 4. Comparison of $\mathrm{H}_{2}$ concentrations along the length of the anode gas channel. 
Fig. 4 shows the hydrogen concentration distribution curves with different anode materials. Similar to the methane, the hydrogen concentration for case II increases faster than for the other two cases, and reaches the same value as the other two cases at the outlet, due to the faster methane steam reforming reaction rate in case II.

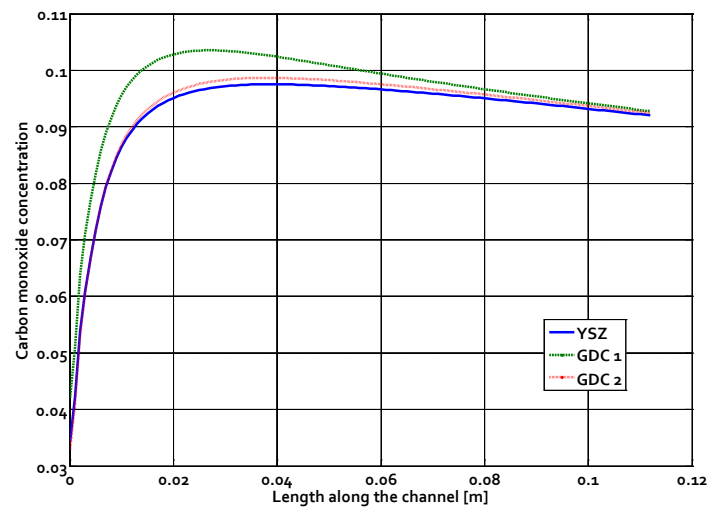

Figure 5. Comparison of CO concentrations along the length of the anode gas channel.

Fig. 5 shows the concentration change of carbon monoxide which is a by-product in the reforming reaction as well as a reactant of the water-gas shift reaction. When the rate of the steam reforming is higher, the rate of carbon monoxide produced from the methane reforming reaction is higher as a consequence and this explains why the $\mathrm{CO}$ concentration is higher for case II. The $\mathrm{CO}$ concentration firstly increases within $0.02 \mathrm{~m}$ from the inlet for all cases, due to the fast methane steam reforming reaction. From this point on, the consumption rate of $\mathrm{CO}$ in the water-gas shift reaction dominates over the production rate of $\mathrm{CO}$ in the reforming reaction for all cases. The bigger consumption rate of $\mathrm{CO}$ for case $\mathrm{II}$ is due to the higher $\mathrm{CO}$ concentration resulting from a faster reforming rate compared with the other two cases. $\mathrm{CO}$ concentration for each case reaches almost the same value at the outlet that is in good agreement with the concentration changes of methane and hydrogen.

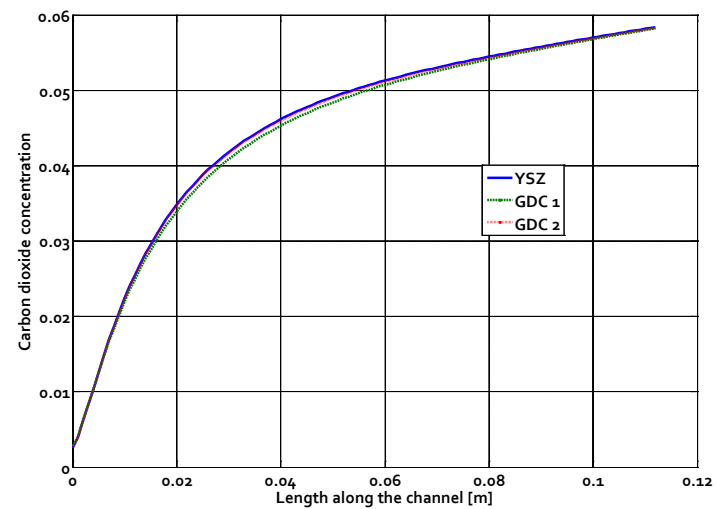

Figure 6. Comparison of $\mathrm{CO} 2$ concentrations along the length of the anode gas channel.

The concentration distribution of $\mathrm{CO} 2$ is presented in Fig. 6. $\mathrm{CO} 2$ is solely produced from the water-gas shift reaction. The $\mathrm{CO} 2$ concentration increases and shows a similar trend in each case. The only difference is the increase rate is slight smaller for case II. This change is accordance with the CO changes shown in Fig. 6. 


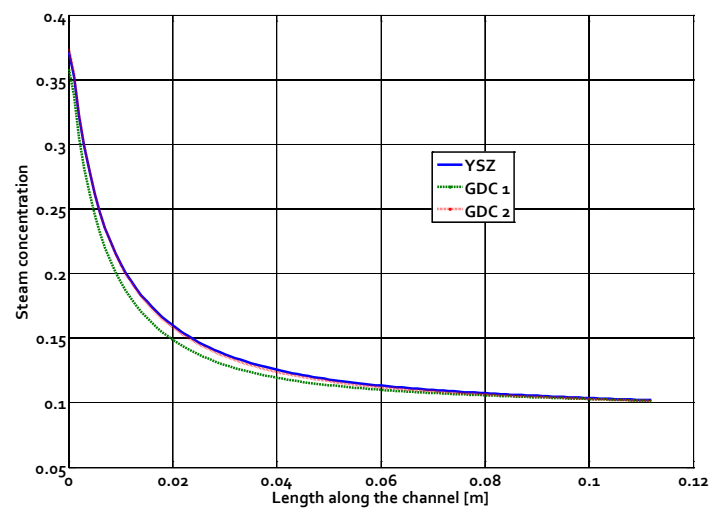

Figure 7. Comparison of steam concentrations along the length of the anode gas channel.

Steam is one of the reactants for both the steam reforming reaction and the water-gas shift reaction, and the concentrations of steam in the channel for the three cases are shown in Fig. 7. Because of the faster reforming reaction rate shown in Fig. 3-4 and the faster water-gas shift reaction rate shown in Fig. 5-6, the decrease rate for steam is bigger in case II. The steam concentration for each case reaches the same value at the outlet. This change is in good agreement with the results for other gas changes shown in Fig. 3-6.

In general, the simulated results of the gas concentration changes are in agreement with the trend observed by Z.Qu et al $(17,18)$ in our group. The modeling results also match well with the previous work from Paradis et al (13) in terms of the gas concentration changes. Further information about the influence of activation energy on the gas compositions along the channel can be found in our previous work (14).

\section{Temperature Changes along The Channel.}

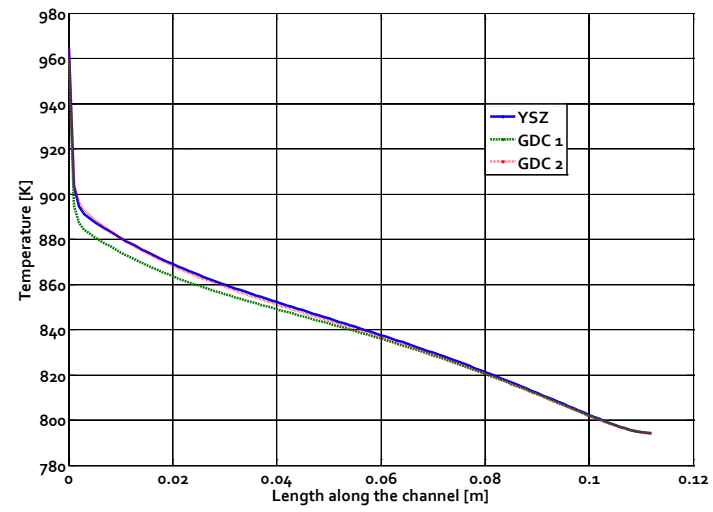

Figure 8. Comparison of temperature changes along the length of the channel.

The temperature changes for each case are presented in Fig. 8. The reason for the lower temperature for case II is that the rate of endothermic reforming reaction is higher, and thus the amount of absorbed heat from the reaction zone is higher for case II. This difference is a result of the combination of lower activation energy and higher thermal conductivity which promotes the reforming reaction rate. 


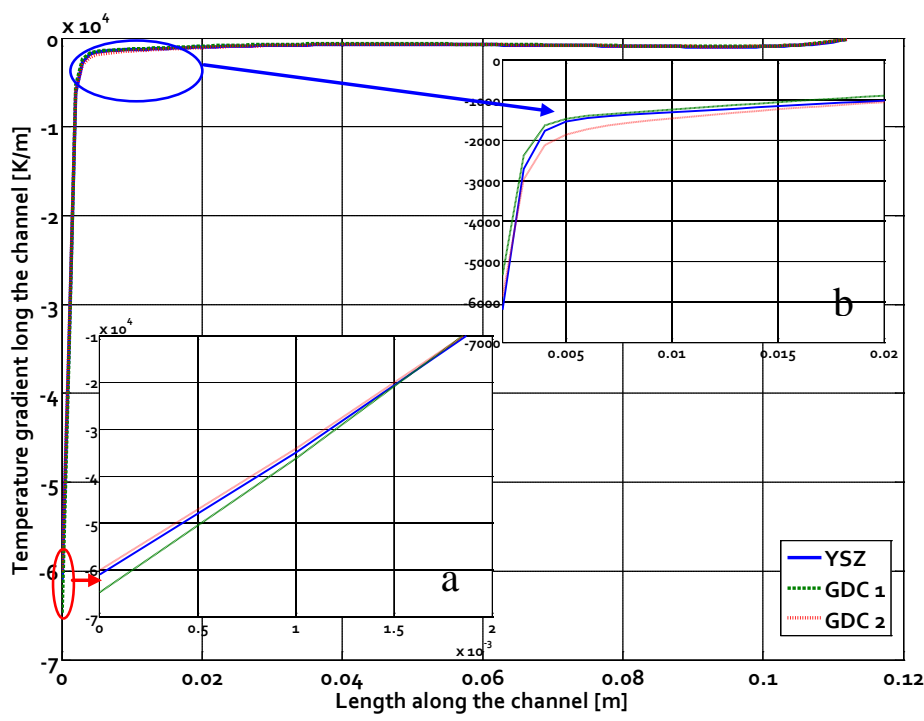

Figure 9. Comparison of temperature gradients along the length of the channel.

The comparisons of temperature gradients along the channel are presented in Fig. 9. Temperature gradient is an important indicator to examine the thermal stress of various materials from different components. For all cases, between $0-5 \mathrm{~mm}$ from the inlet, relatively high temperature gradients are observed compared to the rest part, which are a result of the quick endothermic reforming reaction, and the zoomed part between $0-2 \mathrm{~mm}$ from the inlet is shown in Fig.9 (a). The temperature gradient for case II is the highest among three cases as a result of the fastest reforming reaction. After $2 \mathrm{~mm}$ from the inlet, the temperature gradient for case II is the smallest as shown in Fig. 9(b). While the temperature gradient for case III is the smallest near the inlet till $2 \mathrm{~mm}$, it becomes the biggest after that till $20 \mathrm{~mm}$ which can be seen in Fig. 9 (a)-(b). Therefore, in terms of the thermal stress induced crack of the cell, more attention should be paid to the inlet which shows the highest temperature gradients in the channel. And based on the predicted results with different anode materials, compared with that of Ni-YSZ anodes, more attention should be paid to the Ni-GDC anode since it may cause more severe problems raised by the faster methane steam reforming reaction rate.

\section{Conclusion}

A three-dimensional anode-supported intermediate-temperature planar SOFC channel model with direct internal reforming was used to investigate the influence of anode materials on the cell performance. The experimental results provide an important clue for further investigations of the reaction kinetics in an operating fuel cell with $\mathrm{Ni}-\mathrm{GDC}$ anodes. Certain conclusions can be drawn from the study:

1. Ni-GDC anodes with smaller activation energies and larger thermal conductivity can lead to faster methane steam reforming reaction rates compared with Ni-YSZ anode.

2. SOFCs with different anodes made of different materials may perform differently due to the different reforming kinetics and the different thermal properties. 
3. Significant temperature gradients can be caused by the combination of the different rates of the endothermic methane steam reforming reaction on different anode materials at different locations in the channel. More attention should be paid to the inlet in the fuel channel.

Together with detailed experimental data on methane reforming kinetics in SOFCs, the predicted simulation results can be a guide for future experimental studies and for the design of SOFCs with optimal performance. Further detailed studies of the reforming reaction kinetics should be carried out together with SOFC anode development efforts.

\section{References}

1. D. Mogensen, J. D. Grunwaldt, P. V. Hendriksen, K. Dam-Johansen and J. Nielsen, Journal of power sources, 196, 25 (2011).

2. A. L. Lee, R. Zabransky and W. Huber, Industrial \& engineering chemistry research, 29, 766 (1990).

3. E. Achenbach and E. Riensche, Journal of power sources, 52, 283 (1994).

4. S. Bebelis, A. Zeritis, C. Tiropani and S. G. Neophytides, Industrial \& engineering chemistry research, 39, 4920 (2000).

5. H. Zhu, W. Wang, R. Ran and Z. Shao, International Journal of Hydrogen Energy,38, 3741 (2013)..

6. J. Meusinger, E. Riensche and U. Stimming, Journal of Power Sources, 71, 315 (1998).

7. R. Peters, R. Dahl, U. Kluttgen, C. Palm and D. Stolten, Journal of power sources, 106, 238 (2002).

8. K. Ahmed and K. Foger, Catalysis today, 63, 479 (2000).

9. H. Timmermann, D. Fouquet, A. Weber, E. Ivers-Tiffee, U. Hennings and R. Reimert, Fuel Cells, 6, 307 (2006).

10. E. Vakouftsi, G. Marnellos, C. Athanasiou and F. Coutelieris, Solid State Ionics, 192, 458 (2011)..

11. P. Aguiar, C. Adjiman and N. P. Brandon, Journal of power sources, 138, 120 (2004).

12. Q. Cai, N. P. Brandon and C. S. Adjiman, Frontiers of Energy and Power Engineering in China, 4, 211 (2010).

13. H. Paradis, M. Andersson, J. Yuan and B. Sunden, International Journal of Energy Research, 35, 1107 (2011).

14. L. Fan, E. Dimitriou, M. Pourquie, M. Liu, A. Verkooijen and P. Aravind, International Journal of Hydrogen Energy, 38, 510 (2013)..

15. L. Fan, Z. Qu, M. Pourquie, A. Verkooijen and P. Aravind, Fuel Cells, 13, 410 (2013).

16. Z. Qu, P. Aravind, S. Boksteen, N. Dekker, A. Janssen, N. Woudstra and A. Verkooijen, International Journal of Hydrogen Energy, 36, 10209 (2011).

17. Z. Qu, P. Aravind, N. Dekker, A. Janssen, N. Woudstra and A. Verkooijen, Journal of Power Sources, 195, 7787(2010).

18. Z. Qu, P. Aravind, S. Boksteen, N. Dekker, A. Janssen, N. Woudstra and A. Verkooijen, International Journal of Hydrogen Energy, 36, 10209 (2011).

19. N. Nakagawa, H. Sagara and K. Kato, Journal of power sources, 92, 88 (2001).

20. D. Mogensen, Methane steam reforming kinetics over Ni-YSZ anode materials for Solid Oxide Fuel Cells, Topsoe Fuel Cell A/STopsoe Fuel Cell A/S.

21. J. Xu and G. F. Froment, AIChE Journal, 35, 88 (1989). 
22. K. Ahmed and K. Foger, Catalysis Today, 63, 479 (2000).

23. S. Patel, P. F. Jawlik, L. Wang, G. S. Jackson and A. Almansoori, Journal of fuel cell science and technology, 9, 041002 (2012).

24. M. R. Winter and D. R. Clarke, Acta materialia, 54, 5051 (2006).

25. X. Guo and R. Waser, Progress in Materials Science, 51, 151 (2006). 